\title{
BOOK AND MEDIA REVIEWS
}

\section{Academic Promotion for Clinicians: A Practical Guide to Academic Promotion and Tenure in Medical Schools}

Anne Walling

Cham, Switzerland, Springer Nature, 2018, 174 pp., \$74.99, paperback

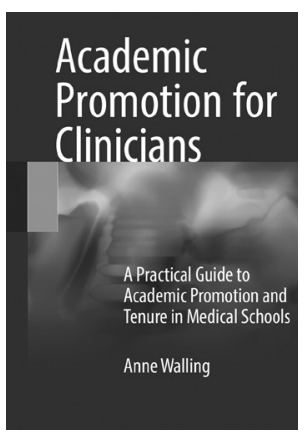

Academic Promotion for Clinicians: A Practical Guide to Academic Promotion and Tenure in Medical Schools was written by Anne Walling, MB, ChB, to help others avoid the traumatic experience she endured as a busy clinician who was unprepared for the academic promotion process early in her career. Written from the perspective of 30 years of experience, much of this obtained as associate dean for faculty affairs at the University of Kansas, Wichita, Dr Walling shares valuable lessons learned and pearls of wisdom with the intent of not just making this process more transparent, but also of helping clinical faculty members to define and prioritize their several missions.

Recognizing that each institution has a unique culture and set of rules for academic promotion, Dr Walling details the challenges of academic promotion for clinical faculty, defines the various tracks available, generally outlines the requirements for promotion, and describes strategies for meeting them. Particularly helpful are her suggestions to develop an educational portfolio to demonstrate scholarship, as proof of scholarship is typically more difficult for clinicians who often lack the peer-reviewed grants, publications, and presentations at prestigious conferences that are traditionally standard. She offers other pearls as well, such as maintaining an ongoing file of teaching and service activities to make documentation of these activities less taxing later, and the importance of tying activities to the medical school's mission to strengthen the file.

Dr Walling then moves on to depict the general process, and provides long-term strategies over the course of one's career to ensure success. Within this blueprint, she discusses excellence in daily activities and leveraging professional activities into scholarship, and provides greater detail regarding archiving data that will provide persuasive support for the quantity, quality, and impact of one's achievements. Finally, she highlights the need for self-reflection after each promotion process to assess one's career course and whether or not correction is needed prior to the next promotion cycle.

This book is well written and full of detailed advice supported by experience. Anyone planning a career in academic medicine and many of those already in the middle of their academic career will find this book an invaluable resource. It will guide a proactive, thoughtful, and intentional planning of one's academic career, and promote record-keeping disciplines and planning that will make documentation of a strong file a readily-tackled task rather than a stressful scramble. I wish Academic Promotion for Clinicians had been available earlier in my career. Rather than taking a reactive approach to academic culture, it would have driven me to mindfully plan and articulate my career goals, and to critically assess how my activities and committees work to further these goals. Even now, I found much of the material helpful as I approach my own merit review as a clinical professor, guiding me to demonstrate how my professional activities align with the institution's expressed goals, and coaching me in presenting the strongest file possible. Dr Walling deserves praise for putting together such an excellent resource for academic clinicians.

doi: 10.22454/FamMed.2020.515192

Holly Salzman, MD

UC San Diego Health

San Diego, CA 


\section{Life Beyond Medicine: The Joys and Challenges of Physician Retirement}

Sharon Rom

Lebanon, NH, University Press of New England, 2019, 177 pp., \$19.95, paperback

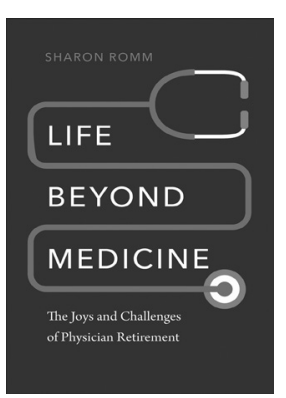

When I was a community-based family doctor, I would tell medical students that I had the best job in the world. I told them that I could help people, use my hands (delivering babies, first-assisting, lump-and-bump surgery), and best of all, hear great stories from my patients. In return, all that my patients asked for were my skills, knowledge, and dedication; this seemed to me to be a fair and rewarding deal! As my practice evolved and I moved through changes in my academic and clinical roles, the job continued to be as good as I could have hoped for. Why ever leave? Well, over the decades, my spirit has remained willing, but my flesh has grown a bit weak; my body and brain told me that I was no longer able to fully keep up my side of the bargain. This year, I've tapered away from clinical work, and am no longer getting paid to be a doctor or teacher. The dreaded word "retired" has been used to describe my current state.

I was excited, therefore, to read Life Beyond Medicine, by Seattle plastic surgeon Sharon Rom, MD, who retooled as a psychiatrist. I was hoping to have a guidebook that would keep me from going off the rails of identity and purpose. It delivered, but only partially. The lead chapter, sadly, was on burnout, and I found it a major turn-off and bummer. The second chapter, "It is Time to Move On," was no better, and I was starting to get demoralized. Fortunately, I had enough momentum to keep on reading, because the subsequent chapters offered hope, encouragement, reflections, and some useful ideas.

The book's focus on the diagnosis and treatment of retirement-related mental health disorders is not surprising, given that the author is a psychiatrist. But it can be disconcerting for those of us whose psychological ailments are minor. Dr Rom uses many statistics that don't offer much insight and are often irrelevant, and the writing was occasionally alarmist regarding all the dangers of boredom and loss of purpose. The author occasionally conflated issues of aging with issues of retirement, which isn't entirely inappropriate; but the reader can usually manage to tease out the differences. Some of the many quotes and anecdotes scattered through the text ring reassuringly true. Most of the examples seemed to relate more to leaving urban practice than to the challenges I face as a retired rural doctor; but rural issues are so often neglected in the house of medicine that I almost didn't notice. The sections on what to do after retirement had some good ideas I hadn't thought of.

The chapter on the emotional challenges of retirement stood out as being nuanced and helpful. The focus on saying goodbye to colleagues was spot-on, but Dr Rom primarily discussed our relationships with other doctors, and left out the office and hospital staff with whom we have grown close. More importantly, she barely mentioned how difficult it is to part with the patients who we have often cared for over 35 or 40 years. We family doctors bond with generations of patients through good times and bad, through birth and death. Those close bonds can be intense, and are not easily parted. Plastic surgeons and psychiatrists may not often have that amazing experience.

I still think that I had the best job in the world, but retirement isn't bad, either. I'm glad to have had some friends and mentors guide me through the process. This book is not an essential aid, but it may be helpful to family physicians transitioning into retirement.

doi: 10.22454/FamMed.2020.689337

\section{Donald Kollisch, MD}

Geisel School of Medicine at Dartmouth -

Community and Family Medicine

Hanover, NH 